\title{
Early changes in quasispecies variant after antiviral therapy for chronic hepatitis B
}

\author{
YUJIAO LIANG ${ }^{1}$, YOSHIHIKO YANO ${ }^{2,3}$, WAHYU ARISTYANING PUTRI $^{2}$, YAN MARDIAN $^{2}$, RINA OKADA $^{3}$, \\ TOSHIHITO TANAHASHI ${ }^{4}$, YOSHIKI MURAKAMI ${ }^{5}$ and YOSHITAKE HAYASHI $^{1}$

\begin{abstract}
${ }^{1}$ Department of Pathology, Division of Molecular Medicine and Medical Genetics; ${ }^{2}$ Centre for Infectious Diseases; ${ }^{3}$ Department of Internal Medicine, Division of Gastroenterology, Kobe University Graduate School of Medicine, Kobe, Hyogo 6500017; ${ }^{4}$ Department of Internal Medicine, Tokushima Prefectural Naruto Hospital, Tokushima 7728503;

${ }^{5}$ Department of Hepatology, Osaka University Graduate School of Medicine, Osaka 5588585, Japan
\end{abstract}

Received October 10, 2017; Accepted January 8, 2018

DOI: $10.3892 / \mathrm{mmr} .2018 .8551$

\begin{abstract}
Hepatitis B virus (HBV) polymerase gene is targeted by nucleos(t)ide analogues (NUC), but it is unclear how HBV quasispecies of whole genome changes during early period of NUC treatment. To understand the unknown region of drug sensitivity and treatment resistance, HBV quasispecies of whole genome during early period of NUC treatment was examined using ultra-deep sequencing. Eleven patients with chronic HBV infection who received NUC treatment were enrolled in the current study. Viral DNA was extracted from serum samples before and early period of NUC treatment. Polymerase chain reaction analysis was subsequently performed on the DNA products. The viral quasispecies of the entire genome was analyzed by ultra-deep sequencing. The regions and positions corresponding to the changes in the quasispecies were investigated before and early period of NUC treatment. The secondary structure changes were predicted by mutations/substitutions detected using Lasergene Protean v14.1 software. The frequency of quasispecies variants increased significantly in the polymerase domain from before to early period of NUC treatment $(3.08 \pm 1.28$ vs. $3.51 \pm 1.47 \%$, $\mathrm{P}<0.008)$, particularly the reverse transcription (RT) domain $(3.76 \pm 1.25$ vs. $4.52 \pm 1.37 \%, \mathrm{P}<0.012)$. In addition, increased variation detected from $\mathrm{HBsAg}$ domain showed statistically significant during NUC treatment $(6.81 \pm 3.26$ vs. $7.81 \pm 3.26 \%$, $\mathrm{P}<0.040$ ). The amino acid (aa) mutations/substitutions were detected and compared from before to early period of treatment.
\end{abstract}

Correspondence to: Dr Yoshihiko Yano, Centre for Infectious Diseases, Kobe University Graduate School of Medicine, 7-5-1 Kusunoki Cho, Kobe, Hyogo 6500017, Japan

E-mail: yanoyo@med.kobe-u.ac.jp

Abbreviations: $\mathrm{HBV}$, hepatitis $\mathrm{B}$ virus; NUC, nucleos(t)ide analogues; $\mathrm{CHB}$, chronic hepatitis B

Key words: HBV, virus quasispecies, nucleotide analogue, ultra-deep sequencing
Interestingly, most of them were located in the RT region (RT1 motif: aa21-aa51) and small $\mathrm{S}$ region in the early duration of NUC treatment. Furthermore, several mutation patterns, such as $\mathrm{cI} 97 \mathrm{~L}$ and $\mathrm{cP} 130 \mathrm{~T}$ showed alterations in the secondary structure and predicted antigenicity of HBV protein. Although the HBV whole genome can be affected by NUC treatment, RT 1 motif region and small $\mathrm{S}$ region are more sensitive to the early period of NUC treatment. This study suggested the initial changes of HBV quasispecies might affect the long-term drug sensitivity and resistance to NUC treatment.

\section{Introduction}

Hepatitis B virus (HBV) infection is a public health problem that causes liver diseases such as chronic hepatitis B (CHB) and progressive liver fibrosis, and may lead to cirrhosis and hepatocellular carcinoma (HCC). Approximately 2 billion people have ever been infected with HBV worldwidely, an estimated 257 million people are chronic carriers of HBV surface antigen (HBsAg), and an estimated 650,000 people will die due to CHB every year $(1,2)$. HBV is a small enveloped virus, with a partially double-stranded DNA genome approximately $3.2 \mathrm{~kb}$ in length. The genome replicates by the reverse transcription (RT) activity of polymerase. The genome has four genes, the polymerase, surface, core, and $\mathrm{X}$ genes with overlapping open reading frames. The most commonly used drugs to treat $\mathrm{CHB}$ are nucleos(t)ide analogues (NUC), which inhibit HBV DNA polymerase activity and suppress HBV replication. Drugs available to treat hepatitis B include lamivudine, telbivudine, entecavir, adefovir, and tenofovir. Although all NUC are effective inhibitors of HBV replication, they are rarely curative, and few patients achieve $\mathrm{HBs} A g$ clearance. Therefore, long-term NUC therapy is necessary for most patients. However, long-term treatment increases the possibility of HBV genomic changes that confer drug or multidrug resistance, and reduce the treatment efficacy in $\mathrm{CHB}$ patients, and could progress to severe liver disease. Drug-resistance mutations were found in approximately $70 \%$ of patients treated with lamivudine for up to 5 years, $29 \%$ of patients treated with adefovir for up to 5 years, $34 \%$ of patients treated with telbivudine for up to 3 years, $1.2 \%$ of patients 
treated with entecavir for up to 6 years (3), and no resistance to tenofovir for up to 7 years (4). The well-known drug resistances (e.g., rtL80I/V, rtI169T, rtV173L, rtL180M, rtA181T, rtT184A, rtV191I, rtS202G, rtM204V, rtM204I, rtV207I, rtN236T, rtM250L) have been reported during long-term NUC treatment (5-7). In addition, $C$ gene deletion mutants and preS gene deletion mutants in patients during NUC therapy may promote vital immune escape resulting in severe liver disease and even hepatic failure (8-10). Cases of severe viral reactivation, viral recurrence, and exacerbation of hepatitis have been reported after discontinuation of NUC treatment (11).

Identification of HBV genotypic NUC resistance is mainly performed by PCR amplification and Sanger sequencing. New technologies, including ultra-deep sequencing methods, that enable high-throughput analysis of thousands of amplified regions were recently developed to increase sequencing capacity while generating clonal sequences (12). Ultra-deep sequencing method is an appealing feature for clinical virologists that are involved in the diagnosis of emerging viral infections, molecular epidemiology of viral pathogens, drug-resistance testing, and also do some basic and clinical research, especially the studies of HBV and HCV (7,12-15). Sanger Sequencing method was widely used for many years and ultra-deep sequencing replaced it recently due to its advantages what is high-throughput sequencing and more sensitive and efficient in detecting minor variants, which can identify mutants that constitute as little as $1 \%$ of the total viral population $(7,14,16)$. Detecting minor population by ultra-deep sequencing assay would be particularly useful for HBV as emerging mutations may be obscured by the ongoing production of mutated variants for a prolonged period (7). In addition, more than one major population in one site can be detected by this assay while Sanger sequencing only can detected one major population in one site. Analysis of the HBV quasispecies in early period of NUC treatment will help us to clarify the substitutions related to genomic sensitivity or resistance to NUC treatment.

So far, although NUC treatment commonly treat patients with hepatitis B infection, the cost of treatment remains economic burden to the patients. Therefore, it is important to choose the appropriate medication and monitor changes in the medication, especially in the early period of treatment. The aim of this study is to understand the unknown region of drug sensitivity and treatment resistance during early period of NUC treatment.

In this study, HBV quasispecies of whole genome during early period of NUC treatment was examined using ultra-deep sequencing. we examined the initial changes in viral quasispecies in relation to drug sensitivity and treatment resistance following NUC therapy. Viral quasispecies were determined by ultra-deep sequencing.

\section{Materials and methods}

Patients and serum samples. Eleven CHB patients without advanced liver disease who received NUC treatment were enrolled in this study. The inclusion criteria were: i) HBV DNA titer $>4 \log$ copies/ml; ii) ALT $\geq 31 \mathrm{IU} / \mathrm{l}$; iii) HBsAg positive for more than 6 months without antiviral therapy; iv) receiving NUC treatment after diagnosis; and v) without advanced liver disease such as liver cirrhosis. Patients co-infected with hepatitis $\mathrm{C}$ virus, hepatitis D virus, or human immunodeficiency virus etc. were excluded from this study. Blood samples were collected before, early period of NUC treatment and after 6 months of NUC introduction. Serum samples were stored at $-80^{\circ} \mathrm{C}$ before analysis. NUC treatment included adefovir (ADV) and entecavir (ETV).

The demographic and clinical data, including age, sex, results of standard test for $\mathrm{CHB}$, were collected from medical record after institutional review board approval was obtained. Written informed consent was obtained from each patient before all the procedures in this study were done. This study was reviewed and approved by the Ethics Committee at Kobe University.

Serological and biochemical tests, and quantification of $H B V$ DNA. The HBsAg titer was determined for all samples using the Lumipulse HBsAg-HQ assay on a fully automated chemiluminescent enzyme immunoassay system (Lumipulse; Fujirebio, Tokyo, Japan). The sensitivity of the Lumipulse HBsAg-HQ assay is $0.005 \mathrm{IU} / \mathrm{ml}$ and its coefficient of variation is $<5.9 \%$ for samples with a low HBsAg titer. Alanine aminotransferase (ALT) levels were determined using standard procedures. The HBV DNA titer was measured using the TaqMan PCR assay (Cobas TaqMan; Roche Molecular Systems, Basel, Switzerland) with a lower limit of detection of $2.1 \log$ copies/ml $(14,17)$.

The Cobas TaqMan methodology uses qPCR to measure PCR product accumulation through a dual-labelled fluorogenic TaqMan probe. The fluorescent signal is generated by the 5'-nuclease activity of the DNA polymerase that digests the probe, separating a fluorescent reporter dye from a quencher dye. The probe specific for the detection of HBV is labelled with a different fluorogenic reporter dye from the QS-specific probe, while both contain the same quencher dye. The accumulation of amplification products is detected by continuously monitoring the release of the fluorescent reporter dyes during the annealing/extension step of each cycle. The PCR cycle at which the increase in normalized fluorescence of a sample exceeds background noise is called the critical threshold value $\left(C_{t}\right)$. The $C_{t}$ is inversely proportional to the initial copy number of the target template (18).

DNA extraction and HBV amplification. HBV DNA was extracted from $200 \mu \mathrm{l}$ of serum using a QIAamp DNA blood Mini kit (Qiagen, Tokyo, Japan) according to the manufacturer's protocol. The entire HBV genome sequence was analyzed using overlapping amplified PCR products. The primers (forward and reverse) were as follows: W1, 5'-GAT TCCTGCTCAAGGAACC-3' (nt 529-547) and 5'-GCCTAC AGCCTCCTAGTAC-3' (nt 1770-1788); W2, 5'-ACTGGG AGGAGTTGGGGGAG-3' (nt 1729-1748) and 5'-GCTGTA GCTCTTGTTCCCAAG-3' (nt 2827-2847); and W3, 5'-GGA CTCATAAGGTGGGAAAC-3' (nt 2461-2480) and 5'-GAC TTGGCCCCCAATACCAC-3' (nt 748-767). The PCR reaction comprised denaturing at $95^{\circ} \mathrm{C}$ for $5 \mathrm{~min}$, followed by 35 cycles of denaturing at $95^{\circ} \mathrm{C}$ for $1 \mathrm{~min}$, annealing at $55^{\circ} \mathrm{C}$ for $1 \mathrm{~min}$ and elongation at $72^{\circ} \mathrm{C}$ for $1.5 \mathrm{~min}$, and a final extension at $72^{\circ} \mathrm{C}$ for $10 \mathrm{~min}$. The presence of an amplified product was confirmed by electrophoresis on $2 \%$ agarose gels, stained 
with ethidium bromide, and visualized on a UV transilluminator. All of the necessary precautions were taken to prevent cross-contamination. A negative control was included in each assay.

Deep sequencing and analysis of amplified products. Ultra-deep sequencing was used to detect variations in the entire genomes of HBV quasispecies. The concentrations of the PCR products were measured using the Qubit high-sensitivity double-stranded DNA assay (Invitrogen; Thermo Fisher Scientific, Inc., Waltham, MA, USA). Next, a library of PCR products $(<500 \mathrm{bp})$ of the viral genome (50 or $0.2 \mathrm{ng}$ ) was prepared using the Nextera DNA sample prep kit (Illumina, Inc., San Diego, CA, USA) or Nextera XT DNA sample prep kit (Illumina, Inc.), according to the manufacturer's instructions. The PCR products were uniformly sheared to 500-bp fragments using these kits, and the PCR product libraries were mixed with $1 \% 8 \mathrm{pM}$ PhiX as a control and run on a MiSeq sequencer (Genome Analyzer; Illumina, Inc.) for paired-end 151 bp sequencing. Finally, image-based detection of the fluorescent signals was performed using MiSeq control software (Illumina, Inc.), and the images were used to develop the sequence data in the FASTQ format. Illumina paired-end sequencing was performed to generate overlapping read pairs (ORP) among relatively short-sequencing-fragment libraries combined with relatively long reads. A quality check and data trimming were necessary before assembling the sequences with Genomics Workbench software version 6.0.1 (CLC bio, Aarhus, Denmark). The sequencing results used in this analysis had a read quality of $>80 \%$ of the consensus sequence estimated from a quality score of $30(\mathrm{Q} 30)$ according to the manufacturer's (Illumina, Inc.) data. ORP and Q30 filtering were used to recover sequencing errors and eliminate any false-positive variants generated by PCR errors during sequencing, to increase the confidence that the sequence reads could be used to detect the viral variants with low abundance. The assembled sequence reads were mapped against the reference HBV genome of genotype C2 (GenBank accession no. AB246344). The viral quasispecies were evaluated in terms of their prevalence in the viral population, which was done using the setting 'read conflict' in Genomics Workbench. The nucleotide(nt) alterations leading to an amino acid (aa) changes were defined as variants. The percentage of the variant population was determined from the proportion of nt substitutions that changed the aa coverage depth (entire sequence reads in each nt position) (14). The viral quasispecies variants detected in $>1 \%$ of the total viral population were classified into a major population ( $>10 \%$ of the total population) and a minor population $(>1 \%$ to $<10 \%$ of the total population). A free DNA translation tool (available at https://www.expasy.org/) was used to compare the variant population before and early period of treatment.

Calculation of antigenicity and secondary structure. To determine whether the aa changes affect the structure of polymerase protein and the antigenicity of $\mathrm{HBsAg}$, hepatitis $\mathrm{B}$ core antigen $(\mathrm{HBcAg})$ and $\mathrm{HBx}$, we used the Jameson-Wolf Antigenic Index Prediction algorithm in Lasergene Protean v14.1 software (DNUCTAR Inc., Madison, WI, USA). The Antigenic Index Prediction analysis uses information from the primary aa sequence to predict the secondary structure (Chou-Fasman and Robson-Garner) (19).

Biostatistical analysis. Statistical analyses were performed with SPSS version 24.0 (IBM Corporation, S\&I, Tokyo, Japan). Shapiro-Wilk test was used for checking the normal distribution of each pair. Differences between groups were examined using paired samples t-test (nominal variables) and Wilcoxon signed rank test (non-normal) and analysis of variance. $\mathrm{P}<0.05$ was considered to indicate a statistically significant difference.

\section{Results}

Clinical characteristics. The subjects' demographic, biochemical and virologic data are shown in Table I. Based on the entire genome, the HBV genotype was $\mathrm{C} 2$ in all eleven patients. The HBV DNA titer in samples collected from early period of NUC treatment was significantly lower than those collected before treatment $(6.09 \pm 0.92$ vs. $8.08 \pm 1.17 \log$ copies $/ \mathrm{ml}$, respectively; $\mathrm{P}<0.000$ ). The HBsAg titer was also lower during early period of treatment than before treatment $(4.02 \pm 0.43$ vs. $4.21 \pm 0.55 \log 10$ $\mathrm{IU} / \mathrm{ml}$, respectively), but it did not show statistically significant between before and early period of treatment $(\mathrm{P}<0.091)$. The ALT level was significantly decreased during early period of treatment compared with before treatment $(93 \pm 35$ vs. $132 \pm 66$ IU/1, respectively; $\mathrm{P}<0.037)$. A mean of $3,146,683 \pm 1,935,574$ (range 898,165 to $6,576,948$ ) bp nucleotides before treatment and $3,171,583 \pm 2,283,172$ (range $1,125,580$ to $8,863,180$ ) bp nucleotides during early period of treatment were mapped into the reference consensus, and mean coverage depth of $82,839 \pm 48,562$ (range 22,023 to 173,168 ) and $100,545 \pm 83,475$ (range 31,440 to 311,408 ) was achieved for each nucleotide site of HBV sequences, respectively. Although we could not calculate statistically due to lack of data, the amount of HBV DNA and HBsAg level have been clearly decreased after six months of NUC treatment (Table I).

Frequency of viral quasispecies variants for each genomic domain. The frequency in major and minor viral quasispecies for each genomic domain was compared between before and early period of NUC treatment (Fig. 1). In the major population, the variation in the polymerase region was significantly greater during early period of NUC treatment than before treatment $(3.51 \pm 1.47$ vs. $3.08 \pm 1.28 \%$, respectively; $\mathrm{P}<0.008$; Fig. 1A). Of note, the variation in the RT domain of polymerase gene and the overlapping small $\mathrm{S}$ domain of the surface gene were significantly different between before and early period of treatment $(3.76 \pm 1.25$ vs. $4.52 \pm 1.37 \%$, respectively, $\mathrm{P}<0.012$; $6.81 \pm 3.26$ vs. $7.81 \pm 3.26 \%$, respectively, $\mathrm{P}<0.040$; Fig. 1 C). In the minor populations, although there were slight variations between before and early period of treatment, these were not statistically significant (Fig. 1B and D).

Amino acid changes in viral population ongoing NUC treatment. The aa mutations/substitutions that accounted for $>1 \%$ of the variations in the total viral population were examined, and the variations were compared between before and early period of treatment. The positions were analyzed if they were detected in $\geq 6$ patients ( $>50 \%$ of subjects). The nt and corresponding aa mutations that differed significantly 
Table I. Demographic, biochemical, and virologic characteristics of the 11 patients.

\begin{tabular}{|c|c|c|c|c|c|c|c|c|c|c|c|c|}
\hline \multirow[b]{2}{*}{ No. } & \multirow[b]{2}{*}{$\begin{array}{c}\text { Age/ } \\
\text { gender }\end{array}$} & \multirow[b]{2}{*}{$\begin{array}{l}\text { Antiviral } \\
\text { treatment }\end{array}$} & \multirow[b]{2}{*}{$\begin{array}{c}\text { Duration } \\
\text { (days) }\end{array}$} & \multicolumn{3}{|c|}{ HBV DNA (logcopy/ml) } & \multicolumn{3}{|c|}{ HBsAg $(\log 10 \mathrm{IU} / \mathrm{ml})$} & \multicolumn{3}{|c|}{ ALT (IU/l) } \\
\hline & & & & Before & Early & $\begin{array}{c}\text { After } \\
6 \mathrm{M}\end{array}$ & Before & Early & $\begin{array}{c}\text { After } \\
6 \mathrm{M}\end{array}$ & Before & Early & $\begin{array}{c}\text { After } \\
6 \mathrm{M}\end{array}$ \\
\hline 1 & $57 / \mathrm{F}$ & ETV & 43 & 7.4 & 5.8 & 3.1 & 3.34 & 3.45 & 3.53 & 120 & 63 & 35 \\
\hline 2 & $30 / \mathrm{M}$ & ETV & 32 & 8.8 & 6.4 & 3.1 & 4.65 & 3.72 & 3.23 & 165 & 90 & 131 \\
\hline 3 & $39 / \mathrm{M}$ & ETV & 148 & 9.3 & 7.3 & 6.1 & 4.31 & 4.45 & 4.35 & 90 & 132 & 86 \\
\hline 4 & $66 / \mathrm{F}$ & ETV & 106 & 9.1 & 6.7 & 5.7 & 4.68 & 4.46 & 4.42 & 62 & 49 & 40 \\
\hline 5 & 28/M & $\mathrm{ADF}$ & 85 & 8.7 & 6.5 & 2.3 & 3.76 & 3.63 & 3.62 & 363 & 82 & 95 \\
\hline 6 & $48 / \mathrm{F}$ & ETV & 127 & 7.0 & 4.5 & 4.3 & 3.37 & 3.36 & 3.35 & 163 & 17 & 18 \\
\hline 7 & 75/M & ETV & 64 & 8.9 & 6.4 & 4.0 & 4.03 & 4.13 & 3.76 & 32 & 43 & 36 \\
\hline 8 & 70/M & ETV & 63 & 9.3 & 6.6 & ND & 4.75 & 4.55 & ND & 123 & 105 & ND \\
\hline 9 & $58 / \mathrm{F}$ & ETV & 14 & 5.7 & 4.8 & 2.7 & 3.95 & 3.91 & 4.09 & 39 & 29 & 24 \\
\hline 10 & $26 / \mathrm{M}$ & $\mathrm{ADF}$ & 123 & 7.2 & 5.1 & 3.7 & 4.78 & 4.13 & 4.00 & 192 & 77 & 56 \\
\hline 11 & $67 / \mathrm{F}$ & ETV & 57 & 7.6 & 6.9 & 4.6 & 4.65 & 4.42 & 4.30 & 99 & 41 & 69 \\
\hline Mean & & & & 8.08 & 6.09 & & 4.21 & 4.02 & & 132 & 66 & \\
\hline SD & & & & 1.17 & 0.92 & & 0.55 & 0.43 & & 93 & 35 & \\
\hline P-value & & & & \multicolumn{2}{|c|}{0.000} & & \multicolumn{2}{|c|}{0.091} & & \multicolumn{2}{|c|}{0.037} & \\
\hline
\end{tabular}

B/E, before treatment/early period of treatment; ETV, entecavir; ADF, adefovir; HBsAg, hepatitis B virus surface antigen; ALT, alanine aminotransferase; SD, standard deviation; ND, no data; After 6M, after 6 months of NUC introduction.
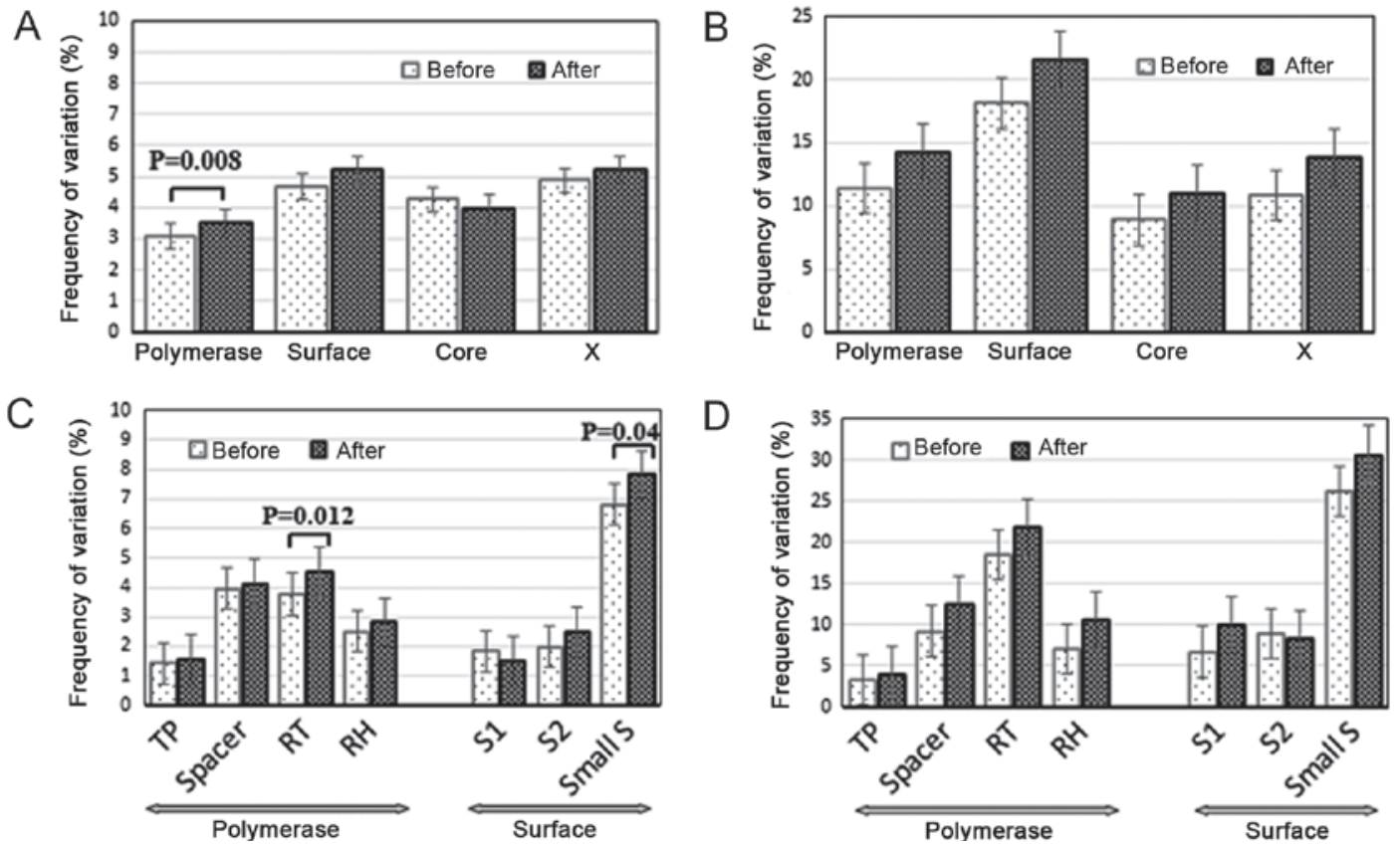

Figure 1. Frequencies of viral variants before and early period of nucleos(t)ide analogues (NUC) treatment in the major (A and C) and minor (B and D) populations. The variation in the polymerase region in the major population was significantly greater in samples collected during early period of NUC treatment than in samples collected before treatment (A). The variation in the RT domain of the polymerase region and the overlapping small S region of the surface gene was significantly different between before and early period of NUC treatment (C). Although there were slight variations in the minor populations between before and early period of treatment, these were not statistically significant (B and D). The value showed as a percentage. (A) frequency of variation in 4 main domains in major population (B) frequency of variation in 4 main domains in minor population (C) frequency of variation in sub-domains in major population (D) frequency of variation in sub-domains in minor population.

are listed in Table II. Numerous mutations were detected in the RT region, which is targeted by NUC. Fig. 2 shows a map of the polymerase domain boundaries. Interestingly, most of these mutations were located in the RT region,
RT1 motif (aa21-aa51) which may affect viral replication. It was suggested that the RT1 motif in the RT region was more sensitive than other subdomains in the early period of treatment. In addition, we found significant variation in the 
Table II. Sites and variations of mutations according to genomic region.

\begin{tabular}{|c|c|c|c|c|c|c|c|}
\hline \multirow[b]{3}{*}{ Position (nt) } & \multirow{2}{*}{\multicolumn{3}{|c|}{ Region (aa) }} & \multirow[b]{3}{*}{$X$} & \multicolumn{2}{|c|}{$\begin{array}{c}\text { Variations of viral } \\
\text { quasispecies }(\%),(\text { mean } \pm \mathrm{SD})\end{array}$} & \multirow[b]{3}{*}{ P-value } \\
\hline & & & & & & & \\
\hline & Polymerase (RT) & Surface (small S) & Core & & Before treatment & of treatment & \\
\hline A162G & & N177S (N3S) & & & $98.40 \pm 1.77$ & $95.84 \pm 7.62$ & 0.037 \\
\hline G217T & V376F (V30F) & & & & $18.15 \pm 5.93$ & $21.02 \pm 5.35$ & 0.029 \\
\hline $\mathrm{G} 217 \mathrm{C} / \mathrm{T}$ & & L195F (L21F) & & & $19.06 \pm 6.18$ & $22.00 \pm 5.55$ & 0.027 \\
\hline G220T & D377Y (D31Y) & & & & $13.12 \pm 3.73$ & $15.03 \pm 3.30$ & 0.044 \\
\hline $\mathrm{G} 220 \mathrm{C} / \mathrm{T}$ & & L196F (L22F) & & & $13.67 \pm 3.88$ & $15.77 \pm 3.38$ & 0.039 \\
\hline A221C & D377A (D31A) & T197P (T23P) & & & $1.54 \pm 0.56$ & $2.01 \pm 0.40$ & 0.027 \\
\hline $\mathrm{A} 221 \mathrm{G}$ & D377G (D31G) & T197A (T23A) & & & $2.89 \pm 1.39$ & $3.71 \pm 0.92$ & 0.013 \\
\hline $\mathrm{A} 221 \mathrm{~T}$ & D377V (D31V) & T197S (T23S) & & & $4.50 \pm 2.69$ & $6.11 \pm 2.18$ & 0.017 \\
\hline $\mathrm{C} 222 \mathrm{~T}$ & & T197I (T23I) & & & $2.02 \pm 1.11$ & $2.70 \pm 0.82$ & 0.018 \\
\hline $\mathrm{T} 228 \mathrm{C}$ & & I199T (I25T) & & & $1.03 \pm 0.46$ & $1.44 \pm 0.26$ & 0.023 \\
\hline A $233 \mathrm{C}$ & H381P (H35P) & T201P (T27P) & & & $10.83 \pm 2.96$ & $12.53 \pm 2.82$ & 0.011 \\
\hline A235C & N382H (N36H) & & & & $5.67 \pm 1.68$ & $7.09 \pm 1.53$ & 0.005 \\
\hline $\mathrm{T} 241 \mathrm{C}$ & T384P (T38P) & & & & $3.68 \pm 1.06$ & $4.32 \pm 1.07$ & 0.041 \\
\hline $\mathrm{T} 247 \mathrm{G}$ & S386A (S40A) & & & & $10.18 \pm 2.25$ & $11.65 \pm 3.34$ & 0.044 \\
\hline $\mathrm{A} 245 \mathrm{C} / \mathrm{T} 247 \mathrm{~A} / \mathrm{G}$ & & S205R (S31R) & & & $12.82 \pm 3.02$ & $14.77 \pm 3.88$ & 0.036 \\
\hline C248G & S386C (S40C) & L206V (L32V) & & & $1.00 \pm 0.49$ & $1.60 \pm 0.49$ & 0.010 \\
\hline T249C & & L206P (L32P) & & & $1.82 \pm 0.77$ & $2.43 \pm 0.89$ & 0.035 \\
\hline $\mathrm{C} 255 \mathrm{~T}$ & & S208L (S34L) & & & $1.13 \pm 0.42$ & $1.55 \pm 0.48$ & 0.022 \\
\hline A272C & Q394P (Q48P) & N214H (N40H) & & & $4.20 \pm 1.72$ & $5.27 \pm 2.28$ & 0.025 \\
\hline A280T & R397W (R51W) & & & & $2.42 \pm 1.20$ & $3.39 \pm 1.72$ & 0.046 \\
\hline G281T & R397M (R51M) & G217W (G43W) & & & $1.61 \pm 0.64$ & $1.97 \pm 0.81$ & 0.043 \\
\hline A293C & H401P (H55P) & $\mathrm{T} 221 \mathrm{P}(\mathrm{T} 46 \mathrm{P})$ & & & $2.30 \pm 1.41$ & $3.05 \pm 1.74$ & 0.013 \\
\hline A333G & & H234R (H60R) & & & $0.92 \pm 0.33$ & $1.21 \pm 0.27$ & 0.043 \\
\hline A337G & T416A (T70A) & & & & $1.02 \pm 0.47$ & $1.39 \pm 0.27$ & 0.023 \\
\hline G633A & & R334K (R160K) & & & $3.76 \pm 4.61$ & $5.48 \pm 4.55$ & 0.036 \\
\hline A1138C & N683H (N337H) & & & & $79.16 \pm 40.77$ & $75.86 \pm 39.95$ & 0.005 \\
\hline G1613A & $\mathrm{R} 841 \mathrm{~K}$ & & & & $14.8 \pm 22.7$ & $19.91 \pm 26.60$ & 0.040 \\
\hline $\mathrm{T} 1753 \mathrm{C}$ & & & & $\mathrm{I} 127 \mathrm{~T}$ & $11.77 \pm 25.07$ & $16.67 \pm 26.71$ & 0.036 \\
\hline A1965C & & & D51A & & $0.93 \pm 0.41$ & $1.33 \pm 0.21$ & 0.036 \\
\hline
\end{tabular}

Values show mean mutation frequency and standard deviation (SD): The mean of the ratio of total mutant clones to total aligned coverage at each nucleotide sites were detected from eleven subjects; nt: nucleotide; aa, amino acid; RT, reverse transcription.

small S region which overlaps with RT region that may affect HBsAg synthesis. In terms of the other regions, we found several substitutions in the core region and $\mathrm{X}$ region but only cD51A, xI127T showed statistically different during early period of treatment.

Changes in the predicted antigenicity of $H B V$ protein. To determine the changes in antigenicity, we used the Jameson and Wolf antigenic index prediction model (19). We used DNAStar software to compare the antigenicity between before and early period of treatment for the aa substitutions/mutations in which the variant population occurred in $>1 \%$ of the total population. The aa variations linked to changes in the secondary structure and their predicted antigenicities are summarized in Table III.

\section{Discussion}

HBV infection is one of the most significant medical problems worldwide. It can cause a variety of liver diseases, including acute hepatitis, chronic hepatitis, liver cirrhosis, and HCC. Therapies for CHB are likely to delay the progression of the severe liver disease. Patients with CHB are treated with NUC, which are effective inhibitors of HBV replication. However, few patients achieve HBsAg clearance, and most patients require long-term NUC treatment. In this study, adefovir and entecavir were selected by the doctor's decision as both of them were first line drug for CHB.

Adefovir belongs to acyclic phosphate class. The structural similarity of adefovir to its natural substrate dATP, together with its small flexible linker, allows it accessibility of adefovir 


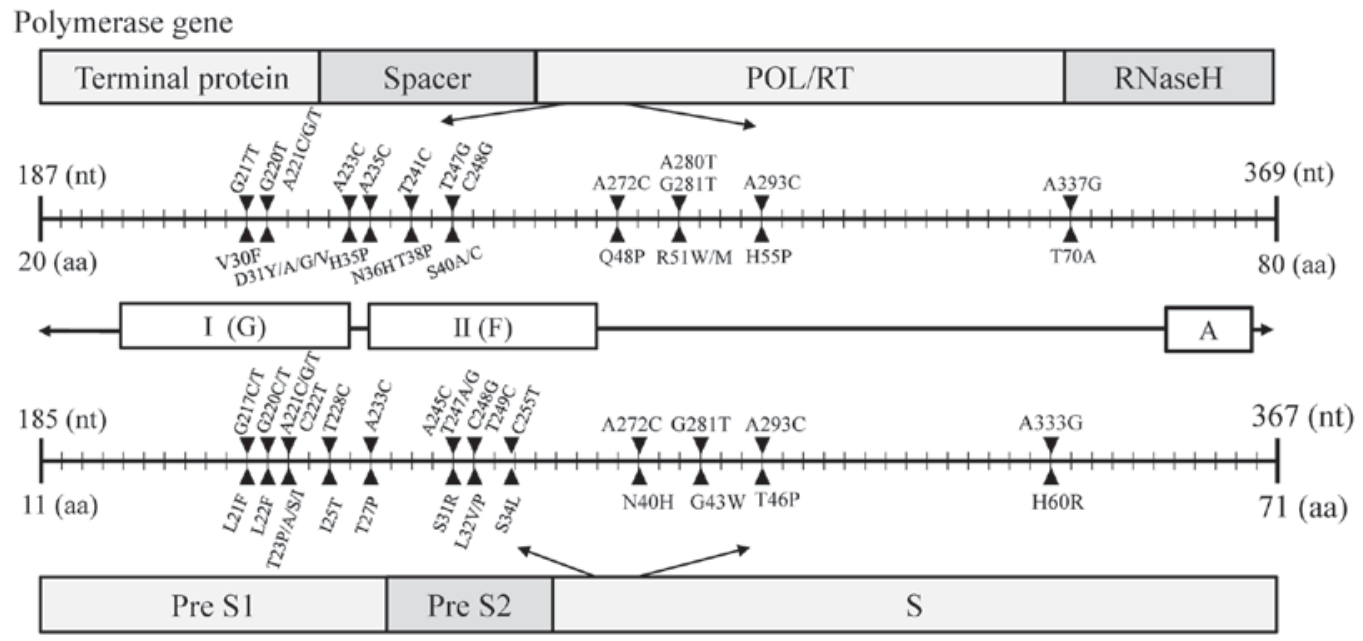

Surface gene

Figure 2. Structures of the polymerase and surface genes. The polymerase gene contains four domains, with seven conserved boxes (A-G) in the RT domain. Boxes A-E are not shown or are incomplete in this figure. The figure also shows part of the small surface gene, which is overlapped by the polymerase gene. Most of mutations which showed significantly different were located in the RT region, RT1 motif (aa21-aa51) which may affect viral replication. From this figure, the RT1 motif in the RT region was more sensitive to NUC treatment than other subdomains in the early-duration of treatment. In addition, the variants detected from S region located in the small S region which overlaps with RT region. NUC, nucleos(t)ide analogues.
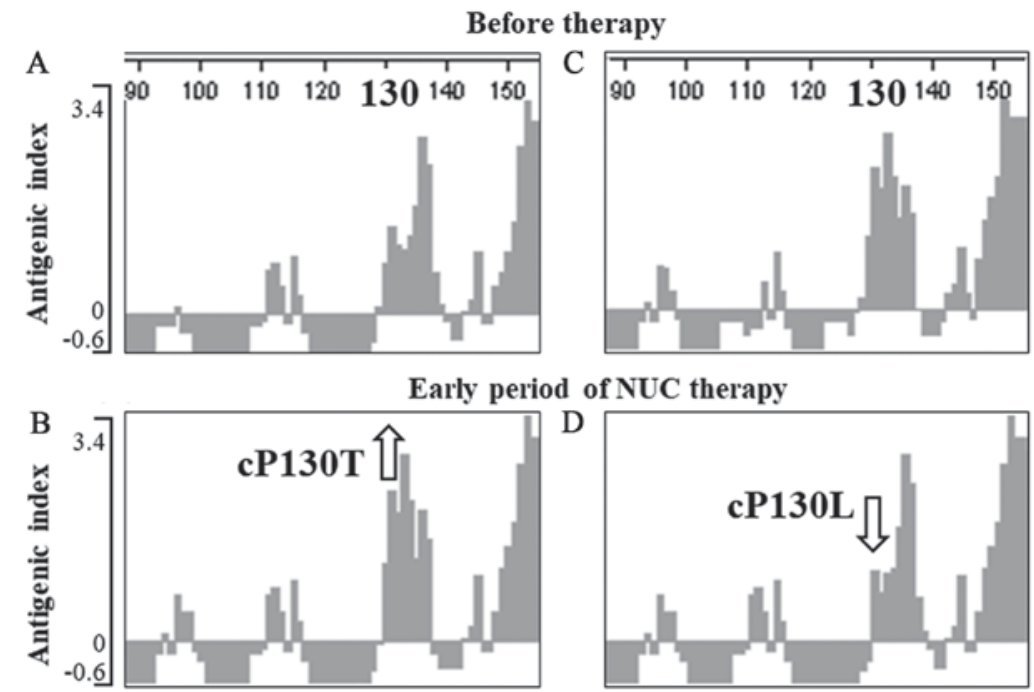

Figure 3. Antigenicity plots based on the amino acid sequences of HBcAg. Two aa variations (cP130T and cP130L) were observed to result in a marked alteration on a large area surrounding the amino acid distribution; the P130T pattern caused an increased antigenicity index in their surroundings (A and B), while the P130L pattern caused marked decreased antigenicity after early period NA treatment (C and D). The major changes in each antigenic index are indicated by an arrow. NUC, nucleos(t)ide analogues; $\mathrm{HBcAg}$, hepatitis B virus surface antigen.

to the polymerase (20). The primary mutations associated with adefovir resistance are rtA181T/V, rtI233V, and rtN236T. The secondary mutations include rtV84M, rtS85A, rtV214A, rtQ215S, rtN238T/D (5-7). The rtN236T mutation may disrupt the hydrogen bond between rtN236 and rtS85 and rtN236 and adefovir diphosphate, thereby decreasing the binding affinity for adefovir. Similarly, other mutations (rtP237H, rtN238T/D, $\mathrm{rtV} 84 \mathrm{M}$, and $\mathrm{rtS} 85 \mathrm{~A}$ ) around this region may also disrupt the triphosphate binding site. The mutation rtA181V/T in domain B may bend the $\alpha$ helices through hydrogen bond formation, and drug resistance may thus result from an allosteric change in the catalytic site. Other mutations (rtV214A, rtQ215S) do not directly interact with the nucleotide but may cause allosteric changes affecting the polymerase function (21-23).
Entecavir belongs to the cyclopentane class and has potent and selective activity against HBV. Two resistance patterns have been recognized: rtM250V + rtI169T + M204V + L180M and $\mathrm{rt184G}+\mathrm{rtS} 202 \mathrm{I}+\mathrm{rtM} 204 \mathrm{~V}+\mathrm{rtL} 180 \mathrm{M}$. The requirement of multiple mutations for entecavir resistance suggests a higher genetic barrier to resistance. The rt250 mutation appears to alter the binding interaction between the primer strand and the template DNA. The rt169 interacts with the dNTP and may work cooperatively with the mutation at rt250. The combination of these mutations may affect elongation of the DNA strand. The rtT184 G and rtS202I mutations interact and affect the hydrophobic core region between the $\alpha$ helix of the DNA template binding region and the $\beta$ sheet, which encodes the 2 catalytic aspartate residues in the $\mathrm{C}$ domain. 


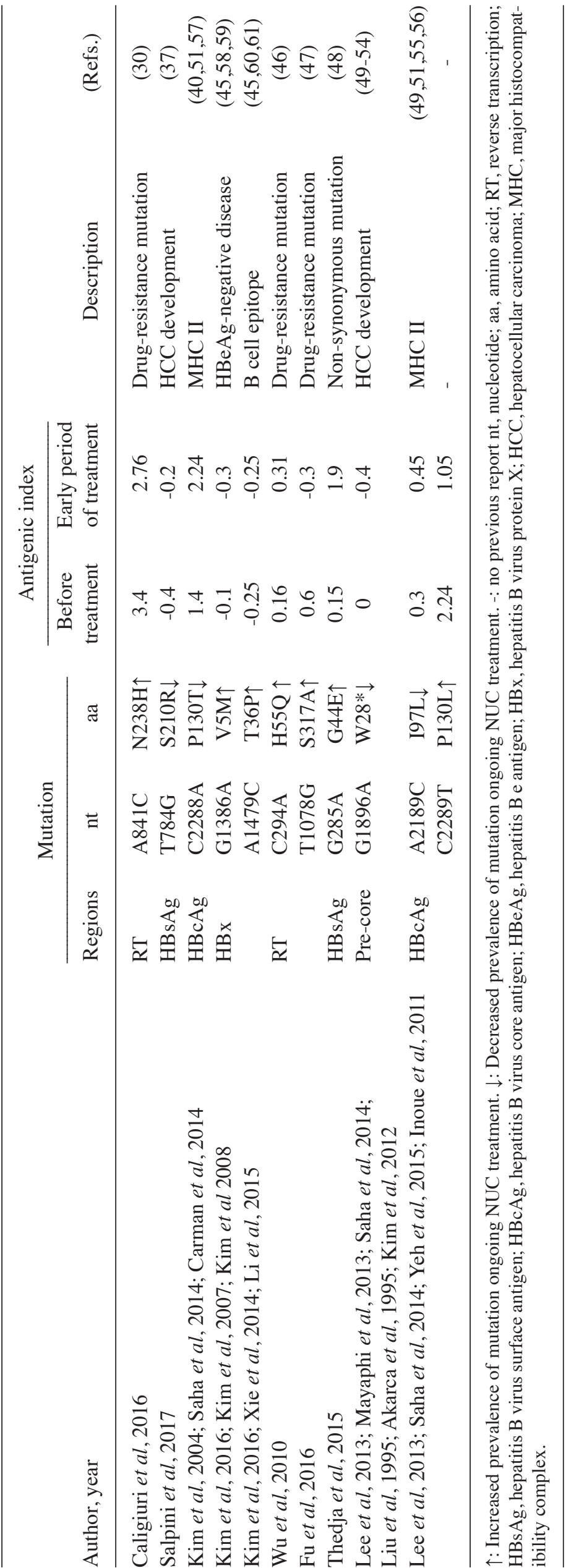


The substitutions at residues $\mathrm{rt} 184$ and $\mathrm{rt} 202$ are predicted to magnify the impact of the lamivudine-resistant mutation in the YMDD loop, affecting substrate discrimination upon nucleotide loading and addition to the primer terminus. In the absence of the lamivudine-resistant mutations, the rtT184 G and rtS202I mutations do not affect the susceptibility of HBV to entecavir (23).

Although these two therapy show the different of mutagenicity, the potency of ADV treatment on HBsAg reduction is not significantly different with that of ETV treatment (24).

The present study revealed significant reductions in the HBV DNA titer and ALT level during NUC treatment (Table I). However, long-term NUC therapy could lead to the emergence of drug resistance and multidrug resistance mutations in the HBV genome. From previous studies (5-10), the well-known resistance mutations in RT region and deletion mutations were not found in this study. The present study should provide further insight into the molecular mechanism of drug resistance in early duration of treatment.

It is perhaps unsurprising that the difference in variation between before and early duration of treatment was greatest in the RT region, a target of NUC therapy. But it is still interesting that the variation in the major population increased during early period of treatment after analyzed the subdomain of RT region. The polymerase gene contains four domains (TP, Spacer, RT, and RH domains). RT plays an important role in viral replication. Because RT lacks a proofreading ability, the error rate and high viral replication rate $\left(10^{11}\right.$ virions per day) contribute to the high mutation rate $\left(10^{-5}\right.$ per nt per generation) $(25,26)$. The $\mathrm{RT}$ region is divided into seven boxes (A-F). The RT1 motif, which contains boxes G and F (aa24-36 and aa37-47, respectively), is required for $\mathrm{He}$ binding $(3,26)$. It was suggested that mutations in the RT1 motif, such as $\mathrm{rtV} 30 / \mathrm{rtD} 31$, may disrupt protein priming and affect viral replication (27-29). In this study, it is suggested that RT1 motif region is more sensitive to NUC treatment and might be a crucial factor for inhibiting the RT activity and suppress HBV replication (Table I) in the early period of NUC treatment.

There are two types of mutations associated with NUC resistance: Primary resistance mutations, which are directly responsible for drug resistance, and secondary mutations, which promote or enhance the replication competence of resistant strains. Several well-known mutations, particularly rtM204I/V (primary resistance mutations) and rtL80V/I (secondary mutations), which occur following long-term treatment and increase viral replication, were not detected in this study. However, we did detect several mutations, notably rtH55Q and rtN238H, which are frequently generated during long-term NUC treatment and are associated with M204I/V (30).

The treatment of CHB with all the by NUCs could result in changes to $\mathrm{HBsAg}$, such as $\mathrm{rtA} 181 \mathrm{~T} / \mathrm{sW} 172 *$. In vitro analysis of rtA181T/sW172* HBV has shown secretion defect of the viral particles to extracellular, resulting in intracellular retention of surface proteins and lower viral loads detected extracellularly (31-33). As shown in this study, the changes in RT 1 motif of polymerase gene can affect small $\mathrm{S}$ gene of surface gene because it overlapped with each other. Therefore, the mutation in small $\mathrm{S}$ gene can affect the synthesis and secretion of HBsAg that become undetectable by current commercially available kit, resulting in 'false' decrease of
HBsAg. In addition, major HBsAg are encoded by small $\mathrm{S}$ gene (the large and middle $\mathrm{S}$ proteins are expressed at levels of about 5-15 and 1-2\% compared with small S protein) (34) and includes the regions involved in the attachment of the virus to hepatocytes as well as the main epitopes recognized by neutralizing antibodies. The aa changes in the surface gene may lead to the adaptive evolution of the viral gene, resulting in altered antigenicity (35). The polymerase gene completely overlaps the HBV surface gene. It is suggested that changes in the $\mathrm{S}$ region where overlapped with polymerase gene (RT1 motif) might decrease the synthesis and secretion of HBsAg. Mutations in the polymerase gene decrease replication activity, but some double mutations in the polymerase gene and the ' $a$ ' determinant region actually increase replication activity (36). In our study, we found no double mutations in polymerase and the 'a' determinant region. However, several secondary resistance mutations were detected in the MHR region, notably sG44E. In addition, the variation in S210R which has been suggested that long-term therapy is associated with reduced cell cycle activity and liver carcinogenesis (37) was detected from early period of treatment. It is showed that it might change the secondary structure and then alter the antigenicity of HBsAg in the early period of treatment.

In this study, the proportion of $\mathrm{rtH} 55 \mathrm{Q}, \mathrm{rtN} 238 \mathrm{H}, \mathrm{rtS} 317 \mathrm{~A}$, sG44E showed an increasing trend during early period of treatment as potential drug resistance mutations in the early duration of treatment. It was considered that these drug resistance mutations may enhance viral replication activity and thus affect the clinical outcome with the persist treatment; SS210R with decreased proportion may indirectly contribute to the activity of these mutations. Therefore, it was suggested that these substitutions should be monitored since the early period of treatment.

The double A1762T and G1764A mutations in the basal core promoter region are associated with altered expression of $\mathrm{HBeAg}$ and viral replication (38). However, the impact of basal core promoter and precore mutations on viral replication remains controversial (39). In this study, the variations A1762T/G1764A were found in 9/11 patients (81.8\%), but there were no significant differences in these variants between before and early period of treatment. The most prevalent mutation in the precore region was G1896A (W28*), which introduces a translational stop codon $\mathrm{W}_{2} 8^{*}$ in the $\mathrm{HBeAg}$ sequence, and halts protein synthesis. A recent meta-analysis indicated that the precore mutation G1896A was significantly associated with increased risk of HCC and progression of liver disease, especially in Asians (40). In the early period of treatment, W28* was detected from three subjects. In other words, NUC treatment could protect or delay the progression to severe. The variations I97L and P130T in the core regions were decreased by NUC treatment. These mutations are located in the MHC class II restricted region and are significantly associated with the pathogenesis of HCC owing to the loss of HBcAg assembly $(41,42)$. It was also reported that the mutation P130T is strongly correlated with the mutation I97L $(43,44)$. It was suggested that these mutations may affect the secondary structure of HBcAg and increased its immunogenicity, attenuating liver carcinogenesis. cP130L with increased proportion more than $15 \%$ during early period of treatment was detected from this study. It was inferred that $\mathrm{cP} 130 \mathrm{~L}$ might alter the secondary structure of $\mathrm{HBcAg}$ and 
lead to reduce the antigenicity of $\mathrm{HBcAg}$ according to predicted antigenicity (Fig. 3). Subsequently, HBcAg could not be recognized by immune system resulting in immune escape. Therefore, it was considered that $\mathrm{cP} 130 \mathrm{~L}$ might be one of immune escape variants resulting in the persistence of HBV. The identification of this hypothesis should be supported by further experiments and more data.

HBx is a multifunctional protein involved in viral replication and affects host gene expression related to HCC (45). HBx also plays important roles in the establishment and maintenance of chronic infection by altering the host's innate immunity. In this study, there were trends towards increased proportion of V5M and T36P following NUC therapy, and these mutations may result in the alteration of the secondary structure of $\mathrm{HBx}$. V5M is common in HCC patients, which suggested that this mutation was a genuine HCC-specific mutation that may play a key role in the progression from chronic hepatitis or liver cirrhosis to HCC (45). By contrast, T36P, which is located in the $\mathrm{B}$ cell epitope region, may lead to persistent infection by providing the virus with a mechanism to evade the host's humoral immune response. In this study, increased variations in V5M or T36P were found from three patients. It is unknown whether the risk of liver cancer is increased due to the aa variations. Regular follow-up and monitoring the progression of liver diseases is important to predict the clinical outcome of patients with CHB.

This study has some limitations. Only a small number of serum samples could be analyzed because of the high cost of the technique and complexity of the analysis for the HBV whole genome. In addition, it is still unclear that resistant mutations will generate after long-term NUC treatment among these patients. These limitations will be solved by long-term follow up and further studies examining additional patients.

In summary, although the HBV whole genome can be affected by NUC treatment, RT 1 motif and small S region are more sensitive to the early period of NUC treatment. This study suggested the initial changes of HBV quasispecies might affect the long-term drug sensitivity and resistance to NUC treatment.

The whole regions of HBV were affected by NUC treatment. Several variations were detected in quasispecies at several positions of the HBV genome. RT1 motif region and small $\mathrm{S}$ region are susceptible in the early period of NUC treatment resulting in inhibiting RT activity and synthesis and secretion of HBsAg. The initial changes of HBV quasispecies might be related to the long-term drug sensitivity and resistance. In this study, it is suggested that B and C subdomains in RT region should not only attached importance to as drug resistance mutations found, others subdomains such as $\mathrm{G}$ and $F$ also should be followed during NUC treatment especially early-period of treatment. These results will be enable us to improve the development of diagnostic tools and establish more efficient therapeutic protocols for CHB.

\section{Acknowledgements}

The authors thank all of the subjects who participated in this research. We also thank the medical staff for helping with performing the study, for their invaluable advice on technical aspects and/or data analysis, and for sample preparation. This study was funded by a Grant-in-Aid from the Ministry of Education, Culture, Sports, Science and Technology, Japan (16H05826), and a Grant-in-Aid from the Japan Initiative for Global Research Network on Infectious Disease (J-GRID) supported by The Ministry of Education, Culture, Sports, Science and Technology, Japan.

\section{References}

1. World Health Organization (WHO): Global Hepatitis Report, 2017. WHO, Geneva, 2017. http://apps.who.int/iris/bitst ream/10665/255016/1/9789241565455-eng.pdf?ua=1. Accessed April 21, 2017.

2. World Health Organization: Guidelines for the Prevention, Care and Treatment of Persons with Chronic Hepatitis B Infection, 2015. WHO, Geneva, 2015. http://apps.who.int/iris/bitst ream/10665/154590/1/9789241549059_eng.pdf?ua=1\&ua=1. Accessed March, 2015

3. Menéndez-Arias L, Álvarez $M$ and Pacheco B: Nucleoside/nucleotide analog inhibitors of hepatitis B virus polymerase: Mechanism of action and resistance. Curr Opin Virol 8: 1-9, 2014.

4. Buti M, Tsai N, Petersen J, Flisiak R, Gurel S, Krastev Z, Aguilar SR, Flaherty JF, Martins EB, Charuworn P, et al: Seven-year efficacy and safety of treatment with tenofovir disoproxil fumarate for chronic hepatitis B virus infection. Dig Dis Sci 60: 1457-1464, 2015.

5. Lei J, Wang Y, Wang LL, Zhang SJ, Chen W, Bai ZG and Xu LY: Profile of hepatitis $\mathrm{B}$ virus resistance mutations against nucleoside/nucleotide analogue treatment in Chinese patients with chronic hepatitis B. Virol J 10: 313, 2013.

6. Rawal RK, Konreddy AK and Chu CK: Mechanism of adefovir, tenofovir and entecavir resistance: Molecular modeling studies of how a novel anti-HBV agent (FMCA) can overcome the drug resistance. Curr Med Chem 22: 3922-3932, 2015.

7. Margeridon-Thermet S, Shulman NS, Ahmed A, Shahriar R, Liu T, Wang C, Holmes SP, Babrzadeh F, Gharizadeh B, Hanczaruk B, et al: Ultra-deep pyrosequencing of hepatitis B virus quasispecies from nucleoside and nucleotide reverse-transcriptase inhibitor (NRTI)-treated patients and NRTI-naive patients. J Infect Dis 199: 1275-1285, 2009.

8. Ji F, Zhou L, Ma S, Li F, Ding H and Zeng C: Dynamic changes of HBV quasispecies and deletion patterns in a chronic hepatitis B patient. J Med Virol 81: 1551-1559, 2009.

9. Günther S, Piwon N, Jung A, Iwanska A, Schmitz H and Will H: Enhanced replication contributes to enrichment of hepatitis B virus with a deletion in the core gene. Virology 273: 286-299, 2000.

10. Zhang D, Dong P, Zhang K, Deng L, Bach C, Chen W, Li F, Protzer U, Ding H and Zeng C: Whole genome HBV deletion profiles and the accumulation of preS deletion mutant during antiviral treatment. BMC Microbiol 12: 307, 2012.

11. Tsuge M, Murakami E, Imamura M, Abe H, Miki D, Hiraga N, Takahashi S, Ochi H, Nelson HC, Ginba H, et al: Serum HBV RNA and HBeAg are useful markers for the safe discontinuation of nucleotide analogue treatments in chronic hepatitis B patients. J Gastroenterol 48: 1188-1204, 2013.

12. Chevaliez S, Rodriguez C and Pawlotsky JM: New virologic tools for management of chronic hepatitis B and C. Gastroenterology 142: 1303-1313.e1, 2012.

13. Barzon L, Lavezzo E, Costanzi G, Franchin E, Toppo S and Palù G: Next-generation sequencing technologies in diagnostic virology. J Clin Virol 58: 346-350, 2013.

14. Yamani LN, Yano Y, Utsumi T, Juniastuti, Wandono H, Widjanarko D, Triantanoe A, Wasityastuti W, Liang YJ, Okada R, et al: Ultradeep sequencing for detection of quasispecies variants in the major hydrophilic region of hepatitis $\mathrm{B}$ virus in indonesian patients. J Clin Microbiol 53: 3165-3175, 2015.

15. Capobianchi MR, Giombini E and Rozera G: Next-generation sequencing technology in clinical virology. Clin Microbiol Infect 19: 15-22, 2013.

16. Zoulim F and Locarnini S: Hepatitis B virus resistance to nucleos(t) ide analogues. Gastroenterology 137: 1593-1608.e1-2, 2009.

17. Shinkai N, Matsuura K, Sugauchi F, Watanabe T, Murakami S, Iio E, Ogawa S, Nojiri S, Joh T and Tanaka Y: Application of a newly developed high-sensitivity HBsAg chemiluminescent enzyme immunoassay for hepatitis B patients with HBsAg seroclearance. J Clin Microbiol 51: 3484-3491, 2013. 
18. Weiss J, Wu H, Farrenkopf B, Schultz T, Song G, Shah S and Siegel J: Real time TaqMan PCR detection and quantitation of HBV genotypes A-G with the use of an internal quantitation standard. J Clin Virol 30: 86-93, 2004.

19. Jameson BA and Wolf $H$ : The antigenic index: A novel algorithm for predicting antigenic determinants. Bioinformatics 4: 181-186, 1988.

20. Westland CE, Yang H, Delaney WE IV, Gibbs CS, Miller MD, Wulfsohn M, Fry J, Brosgart CL and Xiong S; 437 and 438 Study Teams: Week 48 resistance surveillance in two phase 3 clinical studies of adefovir dipivoxil for chronic hepatitis B. Hepatology 38: 96-103, 2003.

21. Yadav V and Chu CK: Molecular mechanisms of adefovir sensitivity and resistance in HBV polymerase mutants: A molecular dynamics study. Bioorganic Med Chem Lett 14: 4313-4317, 2004

22. Ballesteros JA, Deupi X, Olivella M, Haaksma EE and Pardo L: Serine and threonine residues bend alpha-helices in the chi(1)=g(-) conformation. Biophys J 79: 2754-2760, 2000.

23. Ghany M and Liang TJ: Drug targets and molecular mechanisms of drug resistance in chronic hepatitis B. Gastroenterology 132 $1574-1585,2007$

24. Li MR, Xi HL, Wang QH, Hou FQ, Huo N, Zhang XX, Li F and $\mathrm{Xu} \mathrm{XY}$ : Kinetics and prediction of HBsAg loss during long-term therapy with nucleos(t)ide analogues of different potency in patients with chronic hepatitis B. PLoS One 9: e98476, 2014

25. Xu J, Wu B, Wang JH, Huang L, Wang DY, Zhao L, Zhao GP and Wang Y: Pre-existing mutations in reverse transcriptase of hepatitis B virus in treatment-naive Chinese patients with chronic hepatitis B. PLoS One 10: e0117429, 2015.

26. Nowak MA, Bonhoeffer S, Hill AM, Boehme R, Thomas HC and McDade H: Viral dynamics in hepatitis B virus infection. Proc Natl Acad Sci USA 93: 4398-4402, 1996

27. Jones SA, Clark DN, Cao F, Tavis JE and Hu J: Comparative analysis of hepatitis B virus polymerase sequences required for viral RNA binding, RNA packaging, and protein priming. J Virol 88: 1564-1572, 2014

28. Badtke MP, Khan I, Cao F, Hu J and Tavis J: An interdomain RNA binding site on the hepadnaviral polymerase that is essential for reverse transcription. Virology 390: 130-138, 2009.

29. Clark DN and Hu J: Unveiling the roles of HBV polymerase for new antiviral strategies. Future Virol 10: 283-295, 2015.

30. Caligiuri P, Cerruti R, Icardi G and Bruzzone B: Overview of hepatitis $\mathrm{B}$ virus mutations and their implications in the management of infection. World J Gastroenterol 22: 145-154, 2016.

31. Locarnini SA: Hepatitis B virus surface antigen and polymerase gene variants: Potential virological and clinical significance. Hepatology 27: 294-297, 1998.

32. Locarnini SA and Yuen L: Molecular genesis of drug-resistant and vaccine-escape HBV mutants. Antivir Ther 15: 451-461, 2010.

33. Warner $\mathrm{N}$ and Locarnini S: The antiviral drug selected hepatitis B virus rtA181T/sW172* mutant has a dominant negative secretion defect and alters the typical profile of viral rebound. Hepatology 48: 88-98, 2008.

34. World Health Organization (WHO): Hepatitis B: WHO, Geneva, 2002. http://apps.who.int/iris/bitstream/10665/67746/1/WHO_ CDS_CSR_LYO_2002.2_HEPATITIS_B.pdf.

35. Shi $\bar{Y}$, Wei F, Hu D, Li Q, Smith D, Li $\bar{N}$ and Chen D: Mutations in the major hydrophilic region (MHR) of hepatitis B virus genotype C in North China. J Med Virol 84: 1901-1906, 2012

36. MA P: Hepatitis B virus S gene escape mutants. Asian J Transfus Sci 1: 62-70, 2007

37. Salpini R, Surdo M, Warner N, Cortese MF, Colledge D, Soppe S, Bellocchi MC, Armenia D, Carioti L, Continenza F, et al: Novel HBsAg mutations correlate with hepatocellular carcinoma, hamper $\mathrm{HBs} \mathrm{Ag}$ secretion and promote cell proliferation in vitro. Oncotarget 8: 15704-15715, 2017.

38. Silva Souza ACD, Souza Marasca G, Kretzmann-Filho NA, Dall-Bello A, Alexandre Kliemann D, Valle Tovo C and Gorini da Veiga AB: Identification of hepatitis B virus A1762T/G1764A double mutant strain in patients in Southern Brazil. Braz J Infect Dis 21: 525-529, 2017.

39. Zhang ZH, Wu CC, Chen XW, Li X, Li J and Lu MJ: Genetic variation of hepatitis B virus and its significance for pathogenesis. World J Gastroenterol 22: 126-144, 2016.

40. Kim H, Lee SA, Do SY and Kim BJ: Precore/core region mutations of hepatitis B virus related to clinical severity. World J Gastroenterol 22: 4287-4296, 2016.
41. Ceres P, Stray SJ and Zlotnick A: Hepatitis B virus capsid assembly is enhanced by naturally occurring mutation F97L. J Virol 78: 9538-9543, 2004.

42. Ning B and Shih C: Nucleolar localization of human hepatitis B virus capsid protein. J Virol 78: 13653-13668, 2004

43. Hosono S, Tai PC, Wang W, Ambrose M, Hwang DG, Yuan TT, Peng BH, Yang CS, Lee CS and Shih C: Core antigen mutations of human hepatitis B virus in hepatomas accumulate in MHC class II-restricted T cell epitopes. Virology 212: 151-162, 1995.

44. Cheng CP, Lee PF, Liu WC, Wu IC, Chin CY, Chang TT and Tseng VS: Analysis of precore/core covariances associated with viral kinetics and genotypes in hepatitis B e antigen-positive chronic hepatitis B patients. PLoS One 7: e32553, 2012.

45. Kim H, Lee SA and Kim BJ: X region mutations of hepatitis B virus related to clinical severity. World J Gastroenterol 22 : 5467-5478, 2016

46. Wu Z, Han T, Gao Y, Li Y, Liu T, Jing L, Liu L, Du Z, Wu Z and Medical T: Evolution of hepatitis B virus quasispecies during sequential therapy in patients with lamivudine-resistant hepatitis B virus infection. Shijie Huaren Xiaohua Zazhi 18: 779-785, 2010.

47. Fu L, Teng X, Ma Y, Chen S, Xu W, Fu B and Gu H: HBV gene mutations in six multidrug-resistant chronic hepatitis B patients in China. Int J Clin Exp Pathol 9: 2134-2140, 2016.

48. Thedja MD, Muljono DH, Ie SI, Sidarta E, Turyadi Verhoef J and Marzuki S: Genogeography and immune epitope characteristics of hepatitis B virus genotype c reveals two distinct types: Asian and papua-pacific. PLoS One 10: e0132533, 2015.

49. Lee SA, Kim KJ, Kim DW and Kim BJ: Male-specific W4P/R mutation in the pre-S1 region of hepatitis $\mathrm{B}$ virus, increasing the risk of progression of liver diseases in chronic patients. J Clin Microbiol 51: 3928-3936, 2013.

50. Mayaphi SH, Martin DJ, Mphahlele MJ, Blackard JT and Bowyer SM: Variability of the preC/C region of hepatitis B virus genotype A from a South African cohort predominantly infected with HIV. J Med Virol 85: 1883-1892, 2013.

51. Saha D, Pal A, Biswas A, Panigrahi R, Sarkar N, Das D, Sarkar J, Guha SK, Saha B, Chakrabarti S, et al: Molecular characterization of $\mathrm{HBV}$ strains circulating among the treatment-naive HIV/HBV co-infected patients of eastern India. PLoS One 9: e90432, 2014

52. Liu Z, Luo K, He H and Hou J: Hot-spot mutations in hepatitis B virus core gene: Eliciting or evading immune clearance? J Viral Hepat 12: 146-153, 2005.

53. Akarca US and Lok AS: Naturally occurring hepatitis B virus core gene mutations. Hepatology 22: 50-60, 1995.

54. Kim DW, Lee SA, Hwang ES, Kook YH and Kim BJ: Naturally occurring precore/core region mutations of hepatitis B virus genotype $\mathrm{C}$ related to hepatocellular carcinoma. PLoS One 7: e47372, 2012

55. Yeh ML, Peng CY, Dai CY, Lai HC, Huang CF, Hsieh MY, Huang JF, Chen SC, Lin ZY, Yu ML, et al: Pegylated-interferon alpha therapy for treatment-experienced chronic hepatitis B patients. PLoS One 10: e0122259, 2015

56. Inoue J, Ueno Y, Wakui Y, Fukushima K, Kondo Y, Kakazu E, Ninomiya M, Niitsuma $\mathrm{H}$ and Shimosegawa T: Enhanced replication of hepatitis B virus with frameshift in the precore region found in fulminant hepatitis patients. J Infect Dis 204: 1017-1025, 2011.

57. Carman WF, Jacyna MR, Hadziyannis S, Karayiannis P, McGarvey MJ, Makris A and Thomas HC: Mutation preventing formation of hepatitis B e antigen in patients with chronic hepatitis B infection. Lancet 2: 588-591, 1989.

58. Kim H, Jee YM, Song BC, Shin JW, Yang SH, Mun HS, Kim HJ, Oh EJ, Yoon JH, Kim YJ, et al: Molecular epidemiology of hepatitis B virus (HBV) genotypes and serotypes in patients with chronic HBV infection in Korea. Intervirology 50: 52-57, 2007.

59. Kim HJ, Park JH, Jee Y, Lee SA, Kim H, Song BC, Yang S, Lee M, Yoon JH, Kim YJ, et al: Hepatitis B virus X mutations occurring naturally associated with clinical severity of liver disease among Korean patients with chronic genotype C infection. J Med Virol 80: 1337-1343, 2008

60. Xie Y, Liu S, Zhao Y, Guo Z and Xu J: X protein mutations in hepatitis B virus DNA predict postoperative survival in hepatocellular carcinoma. Tumor Biol 35: 10325-10331, 2014.

61. Li W, Goto K, Matsubara Y, Ito S, Muroyama R, Li Q and Kato N: The characteristic changes in hepatitis $\mathrm{B}$ virus $\mathrm{x}$ region for hepatocellular carcinoma: A comprehensive analysis based on global data. PLoS One 10: e0125555, 2015. 